\title{
Remote Triggered Virtual Laboratory on Automotive Engineering
}

\author{
http://dx.doi.org/10.3991/ijoe.v9i6.3075
}

\author{
Bipradip Das, Abhirup Chattopadhyay, S. Fatima and A. R. Mohanty \\ Indian Institute of Technology Kharagpur, India
}

\begin{abstract}
Remote triggered virtual laboratory on automotive systems is an initiative by Indian Institute of Technology Kharagpur, where a student can access and conduct experiments on an internal combustion engine over the internet from remote locations. The lab introduces student to the basic experiments on a single cylinder petrol engine loaded by an eddy current dynamometer. The student has a choice to download the actual experimental data over the internet for subsequent analysis or also browse through a sample calculation. The experimental setup consists of an instrumented single cylinder petrol engine coupled to an eddy current dynamometer which is controlled by a PC based controller. A diverse range of experiments could be performed using this setup which includes noise and vibration monitoring as well as basic performance monitoring of the engine.
\end{abstract}

Index Terms-Engine, power, noise, vibration, load.

\section{INTRODUCTION}

Hands on experience on a real mechanical system which is being studied forms a crucial component of any science and engineering education program. However, sometimes due to lack of an experimental facility, or its availability at some faraway place makes it difficult for the learner to avail that experience. This difficulty could be easily overcome by utilizing the internet resources and by employing smart technological solutions to perform experiments from a remote location. By remote accessing over the internet a sophisticated, expensive instrument available at a distant location a large number of students and researchers can benefit. This is very much a necessity in a developing country like India where at many engineering institutions such experimental and scientific resources are scarce. This initiative requires designing of web enabled experiments for remote operation and viewing which would help everyone in learning basic and advanced concepts of science, engineering and technology.

The remote web based laboratories can be accessed 24 hours a day and therefore is convenient for students to learn as per their convenience and schedule. Integrated with a distant education program, it provides direct handson benefits to students and hence enable students to learn courses which were earlier only possible to be studied oncampus [1]. By employing an automated management system, every student can have fair share of time to conduct the experiment [2]. Further, with this type of sharing of instruments, all the educations institutes are not required to purchase individual set up of the experimental apparatus.
These laboratories would serve both as an instructional tool as well as a self-learning tool [3]. These virtual laboratories can be developed so that they can complement the already existing national programme on technology enhanced learning (NPTEL) of the government of India and provide a near hands-on holistic feel. Such educational resources provide a complete learning where the students can avail the various tools for learning, including additional web-resources, video lectures, animated demonstrations and self-evaluation. These labs would encourage students to conduct experiments by arousing their curiosity. This would help a student in learning the basic and advanced concepts through remote experimentation.

For quite sometime Ministry of Human Resource Development (MHRD) in India has been encouraging for the setting up of virtual laboratories, lab centers and finishing schools. This is in lieu of India's growing population and lack of quality in higher education opportunities in science and engineering. The laboratories will help the learners in the distance education systems. Students who are located in economically backward areas can reap the benefits of quality and relevant education. These laboratories shall provide a platform for the students to conduct experiments in a virtual environment and enhance their capabilities.

Here we have focused our attention to develop a virtual laboratory on automotive engineering. In this study of a remote triggered virtual laboratory on automotive systems, experiment on an internal combustion (IC) engine are done. Because of the global concerns on emission levels and climate change, research around the world are looking into energy sources in automobiles with less carbon content, and thus exploring into the use of alternative fuels like hydrogen fuel cell and lithium-ion base electric battery source. Due to stricter emission norms, the research and developments of automotive engine is focused on optimizing fuel efficiency in an engine, which has led to regulated and metered flow of the air and fuel, along with the close monitoring of the level and composition of the exhaust gases. This has brought in the advances and miniaturization in electronics and in particular the development of embedded engine sensors to be employed in the present day engines. In order to control and regulate the engine performance parameters and its emission levels, a programmable microprocessor based engine control module has almost become mandatory in the engines being manufactured today. In addition to the automotive electronics in the engine, a modern day vehicle has also many electronic sensors in the safety and vehicle stability systems, like the air bag deployment sensor, vehicle traction control sensor, anti- 
lock braking system and the like. And since sensors are installed around the engine and other major sub-systems of the automobile, it has become easier to setup diagnostic modules for ease of fault identification in various subsystems of the automobile.

Another area of interest in automotive engines is in the use of high strength light weight magnesium-aluminum based alloy materials. These materials have been found to have high levels of material damping, which lead to significant levels of radiated noise reduction. Again because of the government regulations on passby noise reduction, manufacturers are doing extensive $R \& D$ in the areas of automotive noise, vibration and harshness (NVH) to reduce the noise level of engines and passby noise levels of vehicles [4-6]. Customers all over the globe are also getting aware of the product quality in terms of $\mathrm{NVH}$ level, which translates to its importance to vehicle manufacturers [7]. In addition several studies have been conducted to utilize active noise and vibration control for designing self-tuning and adaptable engine mounts and vehicle suspension system. Currently, research is focused on driveline dynamics to increase the durability of components subjected to severe fatigue loads [4-6]. Thus it is important that the students in an undergraduate engineering course are exposed to the rudiments of automotive engineering. In the subsequent sections a general description of the laboratory is provided along with the list of various types of experiments which can be conducted on the engine test rig. This will be followed by a discussion on the uniqueness of the virtual laboratory and its future scope.

\section{AUtOMOTIVE ENGINEERING VIRTUAL LABORATORY}

The virtual laboratory at Indian Institute of Technology Kharagpur will provide the students a deeper insight of the automotive sector especially on internal combustion (IC) engine. An engine test rig shown in Fig. 1 fitted with a Honda make G-300 engine has been installed in the laboratory. It is integrated with a computer aided control panel which can be accessed by an engine performance analyzer (EPA) software package. A view of the control panel of the engine test rig which can be accessed over the internet is shown in Fig 2. In the control panel there are digital output displays of the engine torque indicator, rotational speed indicator, temperature, air intake and water flow rate indicator which provides a update on the engines performance parameters.

An eddy current dynamometer is utilized to load the engine, this can be controlled from the control panel, in turn which can be also accessed over the internet. IP based video cameras are installed around the engine test rig with audio and video recording modes so that while conducting experiments remotely the user can have a live video feed from the test location to his computer. However, because of internet bandwidth limitation, the user has the option to change the camera video resolution.

The engine is instrumented with appropriate sensors to measure various engine parameters. A Kistler charge type pressure sensor is installed on the engine cylinder to measure the cylinder pressure. An optical encoder is used to measure the crank position, and a magnetic sensor on a tooth wheel on the crank shaft to measure the rotational speed of the engine. Thermocouples are installed at various locations on the engine test rig to measure the inlet air temperature, exhaust gas temperature, cooling water inlet and outlet temperature for heat load calculations. A turbine flow meter has been installed to measure the cooling water flow rate to the eddy current dynamometer. A strain gauge load cell has been installed to measure load at the dynamometer arm. A collecting tank with an orifice is used to measure the flow rate of the inlet air to the cylinder. A calibrated burette with infrared sensors is used to measure the fuel consumption rate by the engine. A high temperature B\&K 4526 industrial accelerometer has been permanently mounted on the engine cylinder block to measure the engine vibration. Though as an option during measurements, single point laser based transverse vibrations on the engine using a single point laser vibrometer can be made as shown in Fig. 3 .

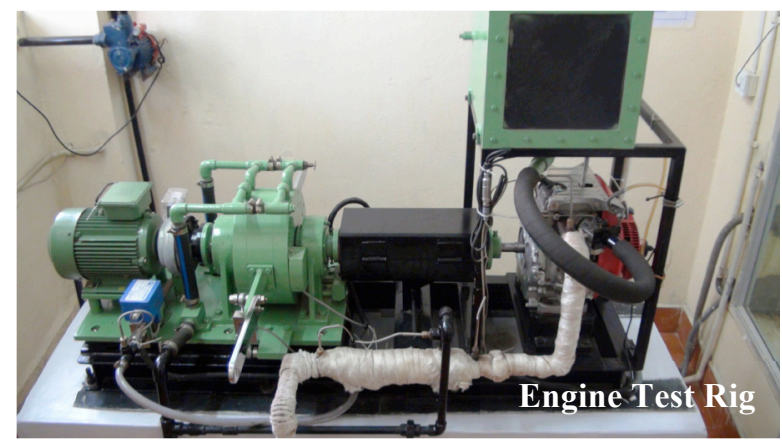

Figure 1. Engine test rig setup installed in the laboratory

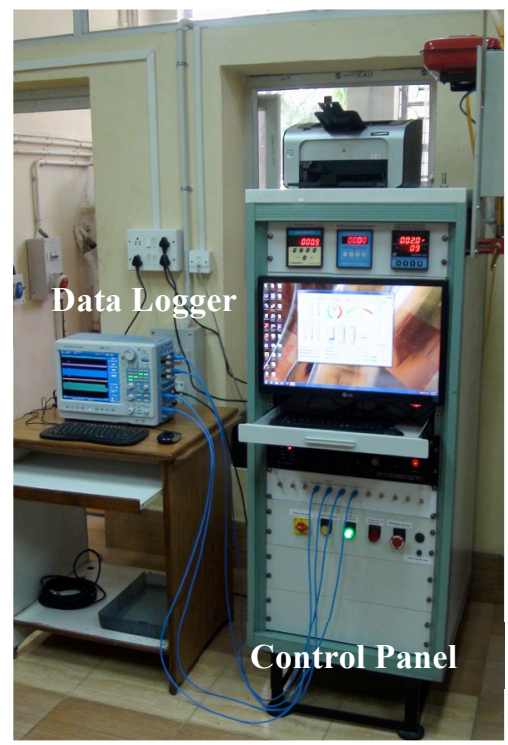

Figure 2. Control Panel which has internet accessibility

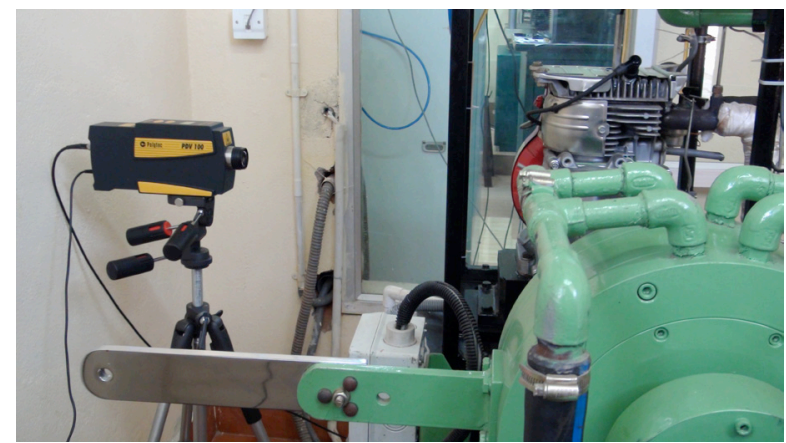

Figure 3. Laser vibrometer for engine vibration measurements 
Further a torsional laser vibrometer is also available to measure the torsional oscillations of the engine crankshaft for different load and speed conditions. Since this is a carbureted engine provisions are made to control the throttle valve from the control panel so that rotational speed of the engine can be changed. The analog outputs from all the above sensors are made available on the control panel, where in a student who is performing experiments has the provision to acquire the analog data for further analysis. In addition a Yokagawa DL850 multichannel data logger is connected to the engine control panel. The data logger is accessible over the internet, so that all the data which are collected from all the sensors while conducting the experiment can be made available to a remote user over the internet online or offline. In order to start the engine from the internet an IP based software with security access is provided so that a user who has pre-registered to conduct the experiments over the internet at an allotted time slot can only start the engine. An IP enabled DC series motor is connected to the engine for this remote triggering purpose.

The engine specifications are as follows:

- Engine Make - HONDA G-300

- Rated Power-5HP@3600 RPM

- Rated Torque-14N-m@2500 RPM

- Cubic Capacity Cylinder - $272 \mathrm{cc}$

- Bore - $76 \mathrm{~mm}$

- Stroke- $60 \mathrm{~mm}$

- Connecting Rod length - $73 \mathrm{~mm}$

- Compression Ratio - 6.5:1

- Type - 4 Stroke, Single Cylinder,

- Air cooled, Petrol Engine

The following experiments can be done on the engine test rig over the internet from a remote location.

1. P-V Diagram of SI Engine

2. Torque-Crank Angle Curve of a SI Engine

3. Load Test on SI Engine

4. Mechanical Efficiency of SI Engine

5. Determination of Cylinder Mean Effective Pressure

6. Engine Health Monitoring by vibration analysis

7. Variation of Exhaust Noise with engine speed

8. Torsional Vibration of an engine

With the help of the Team Viewer Software one can get access to the computerized control panel which has a monitor, installed in it. One can easily regulate the engine input parameters and see the end result using EPA software. A GUI interface of the software is shown in Fig. 4 and Fig. 5.

The EPA software monitors the engine performance by displaying a PV-diagram of the engine and a pressurecrank angle diagram of the engine; and by measuring the following parameters:

BHP, IHP, Mechanical Efficiency, Indicated Mean Effective Pressure, Brake Mean Effective Pressure Brake Thermal Efficiency and Brake Specific Fuel Consumption.

Sample data and calculations for all the eight experiments are also made available at the website for those who would like to browse without actually conducting the experiments. To understand the experi-

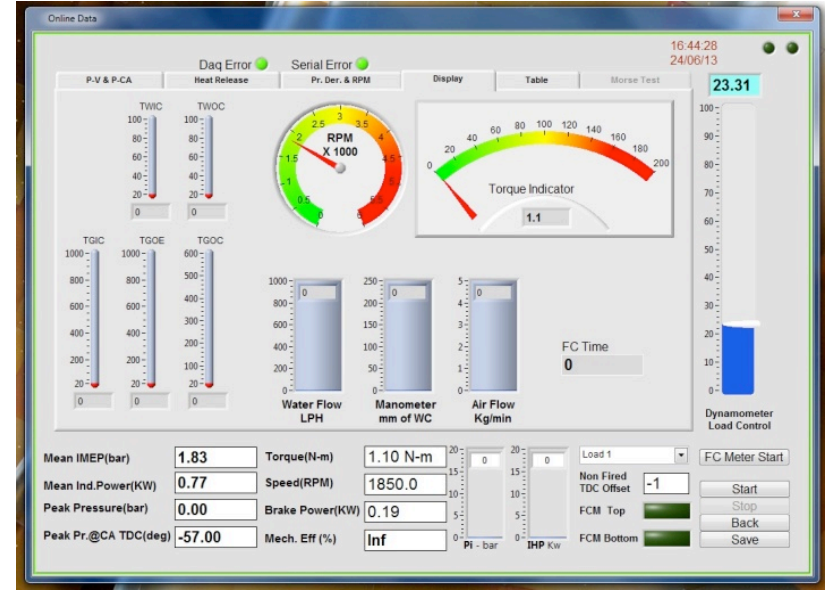

Figure 4. EPA software which can be remotely controlled

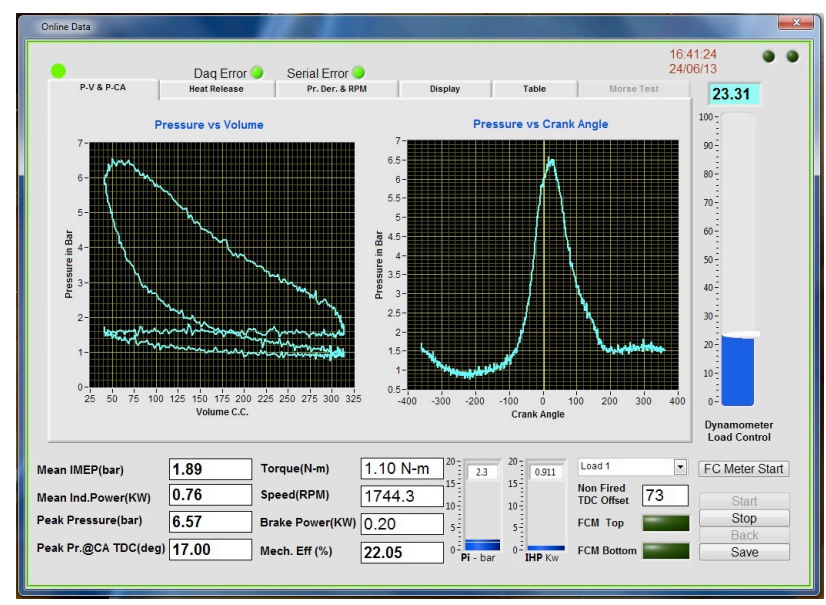

Figure 5. Engine parameters output from EPA software

ments, the following details are provided for each experiment as would be available in a conventional undergraduate engineering laboratory report.

1. Aim and Objective

2. Brief Theory

3. Equipment Required.

4. Procedure/Methodology

5. Observations

6. Sample Calculation

7. Results

8. Discussion and Conclusions

9. Precautions (if any)

10. References

11. Quiz Questions (Optional)

Quiz questions are provided to examine the students understanding on the subject matter. The students who will access the RT-Virtual Lab will find it very easy to understand the experiments and more importantly they can easily relate the theory part with the practical part of it.

\section{SOFTWARE PORTABILITY}

This concept of virtual labs essentially comprises of a user friendly graphical front-end, working in 
synchronization with a back end, possibly consisting of a simulation-engine running on a windows based server.

The free public domain version of the software Team Viewer will be used for internet access into the engine test setup. This software allows the user to get access to another PC or Laptop using LAN connection (or any kind of Internet Connection). A screen shot of the website showing the procedure to access the virtual laboratory through Team Viewer software is shown in Fig. 6. The basic principle behind this software is that users are required to enter the IP address of the host PC or Laptop.

A student can access the Automotive RT-Virtual Lab from anywhere, anytime he/she wants, provided they have pre-registered and have been issued a login ID and password.

\section{FUTURE SCOPE}

This laboratory with the eight experiments empowers students to learn about automotive engineering on the internet by collecting real-time data from a physical IC engine. Other additional important areas of automotive engineering like automotive electronics, propulsion power management system, vehicle dynamics and engine emissions can be added as modules to the developed remote triggered virtual laboratory on automotive engineering in the future.

\section{CONCLUSIONS}

Remote triggered automotive virtual laboratory provides ample opportunities to students at distant location to enhance their learning and educational experience by actually performing an experiment on a real IC engine which they are studying in their text-books. Such a facility is of utmost importance for a developing country like India where baring few educational institute of repute, resources are scarce in other technological educational institutions. This virtual laboratory can be integrated to develop a large educational platform where the students can get to know both the theoretical concepts as well as have a near hands-on experience via the internet, which ultimately leads to knowledge in automotive engineering domain.

\section{ACKNOWLEDGMENT}

The authors would like to acknowledge the help and assistance of Major Manoj Kumar Pandit in installation of the IC engine test setup in the laboratory.

\section{REFERENCES}

[1] K. C. Chu, "What are the benefits of virtual laboratory on studen learning," HERDSA Annual International Conference, Melbourne, 12-15 July, 1999.

[2] R. Byrnes, B. Lo and J. Dimbleby, "Flexible assignment submission in distance learning, "Proceeding of $6^{\text {th }}$ IFIP World Conference on Computer in Education, pp. 305-315, 1995.

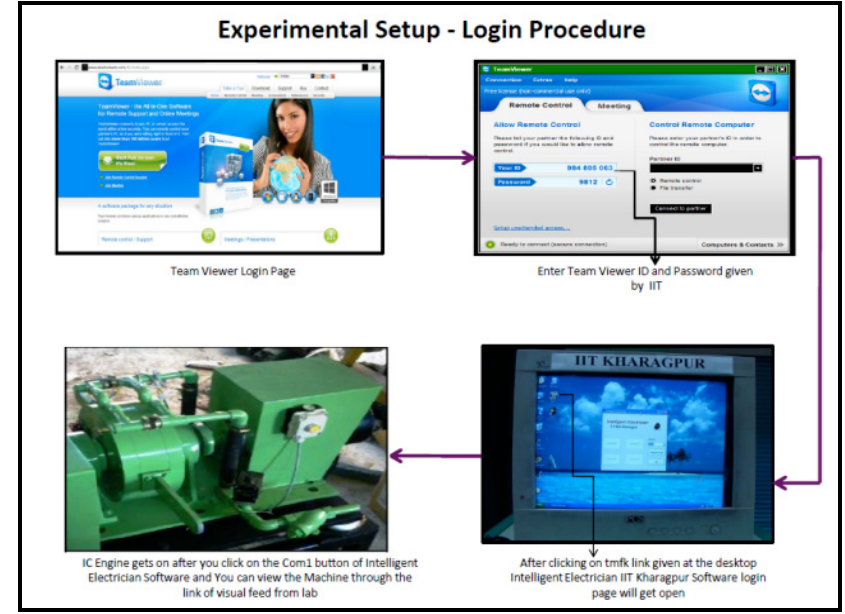

Figure 6. Web template for engine access through internet

[3] P. F. Whelan, "Remote access to continuing engineering education (RACeE)," Engineering Science and Education Journal, pp. 205211, 1997. http://dx.doi.org/10.1049/esej:19970504

[4] M. L. Mathur, R. P. Sharma, Internal Combustion Engine. Dhanpat Rai Publication, 2005.

[5] A. J. Martyr, M. A. Plint, Engine Testing, ISBN: 978-0-75068439-2, 2007.

[6] D. E. Baxa, Noise Control in Internal Combustion Engines, John Wiley \& Sons, 1982.

[7] A. R. Mohanty and S. Fatima, "An overview of automobile noise and vibration control," Noise and Vibration Worldwide, vol. 44 pp. 10-19, 2013. http://dx.doi.org/10.1260/0957-4565.44.6.10

\section{AUTHORS}

Bipradip Das is a third year undergraduate engineering student at the Indian Institute of Technology Kharagpur who worked as a summer intern .(e-mail: dasbipradip@iitkgp.ac.in)

Abhirup Chattopadhyay was a summer intern at the Acoustics and Condition Monitoring Laboratory of the Indian Institute of Technology Kharagpur. (e-mail: abhirup017@gmail.com)

S. Fatima is a Ph.D. student at the Indian Institute of Technology Kharagpur working in the areas of machinery condition monitoring and she also has a Master degree from the same institute. (e-mail: fatima.iitkgp@gmail.com)

A. R. Mohanty is a professor of mechanical engineering at the Indian Institute of Technology Kharagpur. Prof. Mohanty holds a Ph.D from the University of Kentucky, USA, Details about the laboratory can be found at www.iitnoise.com. (e-mail: amohanty@mech.iitkgp.ernet.in)

This work in establishing the virtual laboratory was supported in part by ministry of human resources development, government of India. Submitted 31 July 2013. Published as res-ubmitted by the authors 12 October 2013. 